\title{
Key aspects of stratospheric tracer modeling using assimilated winds
}

\author{
B. Bregman, E. Meijer, and R. Scheele \\ Royal Netherlands Meteorological Institute, P.O. Box 201, 3730 AE, De Bilt, The Netherlands
}

Received: 3 February 2006 - Published in Atmos. Chem. Phys. Discuss.: 6 June 2006

Revised: 7 September 2006 - Accepted: 26 September 2006 - Published: 6 October 2006

\begin{abstract}
This study describes key aspects of global chemistry-transport models and their impact on stratospheric tracer transport. We concentrate on global models that use assimilated winds from numerical weather predictions, but the results also apply to tracer transport in general circulation models. We examined grid resolution, numerical diffusion, air parcel dispersion, the wind or mass flux update frequency, and time interpolation. The evaluation is performed with assimilated meteorology from the "operational analyses or operational data" (OD) from the European Centre for MediumRange Weather Forecasts (ECMWF). We also show the effect of the mass flux update frequency using the ECMWF 40-year re-analyses (ERA40).

We applied the three-dimensional chemistry-transport Tracer Model version 5 (TM5) and a trajectory model and performed several diagnoses focusing on different transport regimes. Covering different time and spatial scales, we examined (1) polar vortex dynamics during the Arctic winter, (2) the large-scale stratospheric meridional circulation, and (3) air parcel dispersion in the tropical lower stratosphere.

Tracer distributions inside the Arctic polar vortex show considerably worse agreement with observations when the model grid resolution in the polar region is reduced to avoid numerical instability. The results are sensitive to the diffusivity of the advection. Nevertheless, the use of a computational cheaper but diffusive advection scheme is feasible for tracer transport when the horizontal grid resolution is equal or smaller than 1 degree. The use of time interpolated winds improves the tracer distributions, particularly in the middle and upper stratosphere. Considerable improvement is found both in the large-scale tracer distribution and in the polar regions when the update frequency of the assimilated winds is increased from 6 to $3 \mathrm{~h}$. It considerably reduces the vertical dispersion of air parcels in the tropical lower stratosphere.
\end{abstract}

Correspondence to: B. Bregman

(bregman@knmi.nl)
Strong horizontal dispersion is not necessarily an indication of poor wind quality, as observations indicate. Moreover, the generally applied air parcel dispersion calculations should be interpreted with care, given the strong sensitivity of dispersion with altitude.

The results in this study provide a guideline for stratospheric tracer modeling using assimilated winds. They further demonstrate significant progress in the use of assimilated meteorology in chemistry-transport models, relevant for both short- and long-term integrations.

\section{Introduction}

Global three-dimensional chemistry transport models (hereafter referred to as CTMs) driven by actual meteorology from numerical weather predictions are crucial for the interpretation of many observational data. The great advantage is the direct comparison with observations by their ability to utilize actual meteorology to drive the model transport. CTMs are thus ideally designed for detailed sensitivity studies of key processes important for climate, which would be computationally too expensive for Chemistry-Climate Models (CCMs). Major areas of interest are the polar regions, owing to the prevailing chemical ozone loss during winter and their sensitivity towards climate change, and the tropical region where the main entrance of air into the stratosphere is located (Holton et al., 1995).

The ability of a direct comparison with observations also allows model sensitivity studies to investigate basic model parameters, such as grid resolution and advection, but also the quality of the mass fluxes (or wind vectors) and the way the meteorological information is implemented in the CTM.

The impact of grid resolution on the atmospheric composition remains an important subject of discussion. Searle et al. (1998) show that a horizontal resolution of $3^{\circ}$ is sufficient to calculate polar chemical ozone loss. In contrast,

Published by Copernicus GmbH on behalf of the European Geosciences Union. 
Marchand et al. (2003) found substantial differences after increasing their model resolution from $2^{\circ} \times 2^{\circ}$ to $1^{\circ} \times 1^{\circ}$. Another model study also focused on the effect of spatial resolution in the polar region by evaluating methane distributions (van den Broek et al., 2003). An important outcome was the significant overestimation of methane in the lower stratosphere at the edge and inside the polar vortex. An increase of the horizontal grid resolution to $1^{\circ} \times 1^{\circ}$ gave negligible improvement and thus indicated very small sensitivity to horizontal resolution. A similar conclusion came from Searle et al. (1998) and Strahan and Polansky (2006). However, Searle et al. (1998) stated that the sensitivity to resolution depends on the diffusivity of the advection scheme. The results of this study underlines this conclusion, contrast our earlier findings by van den Broek et al. (2003) and are more in line with those from Marchand et al. (2003).

However, the investigation of grid resolution in the polar regions is complicated by the commonly applied grid cell or mass flux merging which is done to avoid numerical problems. CTMs and CCMs suffer from numerical instability in regions of strong zonal winds and relatively small grid cells. The most critical regions are located at the poles, in particular during the winter, but also in the vicinity of storm tracks. Negative tracer mass can occur when the transport distance during one advection time step exceeds the size of the grid cell, the so-called Courant-Friedrichs-Lewy (CFL) criterion. This is generally solved by reducing the grid resolution or by averaging the wind vectors or mass fluxes, but its impact on tracer transport has sofar not been investigated.

An obvious alternative solution would be to reduce the advection time step, but this would lead to excessively small time steps. To overcome this difficulty we introduced an iteration procedure for tracer advection in the TM5 model with locally adjusted time steps (Krol et al., 2005). This iteration procedure allowed us to omit the model grid averaging (apart from the pole cap itself). In Krol et al. (2005) the focus was on the troposphere. In this study we will demonstrate the dramatic impact on the stratospheric tracer distribution.

Another crucial factor for tracer transport is the quality of the winds provided by the numerical weather predictions. The winds are subject to data assimilation within the model prediction and are often referred to as Data Assimilation System or DAS winds (Schoeberl et al., 2002). The quality of particularly the stratospheric winds is affected by the presence of spurious variability or "noise", inherently introduced through the assimilation procedure, either through a lack of suitable observations or by inaccurate treatment of the model biases. This unwanted variability causes enhanced dispersion or spurious mixing that accumulates in time (Stohl et al., 2004; Tan et al., 2004). Hence, the impact of dispersion increases with increasing dynamic time scales. It may therefore not be a serious problem for the troposphere where the dynamic turnover times are relatively short. However, the stratospheric circulation contains much longer time scales where spurious variability in DAS winds becomes very crit- ical. One of the consequences is enhanced dispersion and an enforced large-scale stratospheric meridional circulation, causing tracer residence times to be considerably shorter than observed (Schoeberl et al., 2002; Douglass et al., 2003; Meijer et al., 2004). The most critical region is the tropical lower stratosphere, where the majority of the air enters the stratosphere. Moreover, this is a very complicated region for data assimilation due to a lack of observations and because the tropical atmosphere is not in geostrophical balance, which complicates proper treatment of model biases.

Meijer et al. (2004) and Scheele et al. (2005) show that the intensity of dispersion in the DAS winds increases when the assimilation procedure is less accurate or less sophisticated. For example, the ECMWF utilizes three- and fourdimensional assimilation procedures (3DVAR and 4DVAR respectively). 4DVAR is a temporal extension of 3DVAR, and thus more accurate but also computationally more expensive. A comprehensive description of the ECWMF assimilation procedures can be found at http://www.ecmwf.int. A major difference is that 4DVAR produces physically more balanced winds for each model time step, due to the inclusion of time. Because of computational expenses the ECMWF 40year re-analyses (ERA40) have been produced with 3DVAR, while the operational data, analyses and forecasts (referred to as "Operational Data" or OD) have been produced with 4DVAR. Comparing both data sets thus yields information about the impact of assimilation accuracy on tracer transport.

Ozone is a useful tracer, since its distribution is very vulnerable to the strength of large-scale stratospheric circulation. Laat et al. (2006) and Noije et al. (2004) show a very strong accumulation of ozone in the extra-tropical lower stratosphere when using ERA40 winds, resulting in significant overestimation compared to observations. When applying OD winds, the agreement becomes much better. Indeed, Noije et al. (2004), Simmons et al. (2005) and Scheele et al. (2005) have shown that OD winds contain less dispersion than ERA40 winds in the tropical lower stratosphere and provide more realistic extra-tropical downward ozone fluxes (Noije et al., 2004) and more realistic stratospheric residence times (Meijer et al., 2004). However, even with OD the circulation remains too strong (Laat et al., 2006), which has led to the practical decision to constrain stratospheric ozone down to $100 \mathrm{hPa}$ in the extra-tropics with ozone climatology (Noije et al., 2004) for the tropospheric multi-year IPCC chemistry-transport runs . However for coupled tropospherestratosphere runs this solution is undesirable.

Recently, a comprehensive model intercomparison was performed with winds and temperatures from a variety of data assimilation systems, focusing on the 2002 Antarctic vortex split (Manney et al., 2005). They show substantial differences between the models that apply different DAS, with operational (4DVAR) analysis performing better than re-analysis (3DVAR) data, consistent with the studies described above. 
Despite shortcomings in ERA40 winds, the dynamical variability can be simulated quite well (Hadjinicolaou and Pyle, 2005; Chipperfield, 2006). This is in line with a comparison between DAS winds from different numerical weather predictions, where ERA40 winds were found to agree excellent with observed variability (Randel et al., 2003). Therefore the ERA40 data is regarded as one of the most valuable meteorological data sets for long-term trend studies. It is for this reason that we added ERA40 to our diagnostics. The crucial question is if there are ways to use ERA40 data in CTMs that improve the stratospheric tracer transport.

One relevant aspect not commonly addressed in CTM studies is the effect of the update frequency of the assimilated winds and the variability within the time interval on the modeled tracer distributions. Generally the winds are updated every $6 \mathrm{~h}$. However, stratospheric dynamical variability occurs on time scales shorter than $6 \mathrm{~h}$ (Shepherd et al., 2000; Manson et al., 2002), so that a considerable part of real variability is neglected. Additionally, the winds can be assumed constant over this time interval (instantaneous), averaged or interpolated in time. Instantaneous winds introduce discontinuities when changing time interval, leading to spurious variability (aliasing), while averaging can be regarded as a (strong) wave filter. Examining ERA40 winds with the FLEXPART trajectory model (Stohl et al., 2002), Legras et al. (2005) show that decreasing the meteorological update time interval from 6 to $3 \mathrm{~h}$ reduces spurious motions in the stratosphere considerably.

There have only been very few model studies using 3hourly meteorological data in CTMs (Wild et al., 2003; Legras et al., 2005; Berthet et al., 2006). Moreover, a more general evaluation at different spatial scales and including the effect of interpolation within the time interval has not yet been performed, which is the aim of this study.

The important question is whether we will be able to perform meaningful multi-year tracer integrations applying DAS winds. The answer depends on the progress in improving DAS wind quality and the way they are applied in global models. Improving the quality of DAS winds is an ongoing activity and progress is being made in filtering techniques, treatment of the error covariances and bias corrections (Polavarapu et al., 2005), Simmons, personal communication). In this study we concentrate on how DAS winds are applied in CTMs.

To evaluate all these key aspects for tracer transport we perform a variety of integrations, examining different model grid resolutions, as well as different time intervals of the DAS winds, including time interpolation effects. We use $\mathrm{CH}_{4}$ as a passive tracer to focus on polar transport in a similar setup as in van den Broek et al. (2003). The reason for this experiment is not to provide a detailed evaluation of transport in the Arctic polar vortex, but rather to supply an update of our previous model evaluation.
We further apply the age of air diagnose as a first-order approximation of the impact on the large-scale stratospheric meridional circulation and perform trajectory calculations to examine the degree of dispersion in the tropical lower stratosphere in the assimilated winds. All CTM experiments have been performed with ECMWF operational analyses, while the ECMWF re-analyses, ERA40, has been used in trajectory experiments to illustrate the effect of meteorology update frequency. We have decided not to use ERA40 fields in our CTM studies since it is known that the stratospheric tracer distributions are of worse quality using re-analyses data instead of operational analyses.

The outline of this paper is as follows. We first briefly describe TM5 and the recent updates. The next section describes the model sensitivity experiments for the polar region, the general stratospheric circulation and dispersion in the tropical lower stratosphere, which is followed by a section describing the results for each diagnostic. Some aspects subject for discussion are addressed in the Discussion section, which is followed by the section Conclusions.

\section{Model description}

The CTM we use in this study is the global Tracer Model, TM5, which is a grid point Eulerian 3-D CTM and an extended version of the TM3 model. The TM3 model has been used widely in the modeling community (e.g. Dentener et al., 1999; Peters et al., 2001; Houweling et al., 1998; Van den Broek et al., 2000; Bregman et al., 2001, 2002). The original version of the model has been developed by Heimann (1995); Heimann and Keeling (1989). TM5 uses forecasts of the European Centre for Medium-range Weather Forecasts (ECMWF) to drive the transport with a default update time interval of $6 \mathrm{~h}$. It further uses mass fluxes for advection of the tracers as described in van den Broek et al. (2003). The model contains a Cartesian grid and consists of a two-way nested grid zooming over selected areas by increasing the horizontal resolution, currently up to $1^{\circ} \times 1^{\circ}$. The model further contains hybrid $\sigma$-pressure levels with the top level at $0.1 \mathrm{hPa}$. The representation of the model winds has been adjusted to assure mass conservation following the method of Segers et al. (2002), which improved the representation of the model tracer fields significantly (Bregman et al., 2003).

An important feature of the TM5 zoom version is the mass consistent two-way nesting that allows global studies including zoom areas. Because of the grid zooming capability the model architecture has changed fundamentally. The model structure and the zooming concept have been described in detail and the model was successfully validated for the lower troposphere by Krol et al. (2005).

A validation of stratospheric tracers was performed by van den Broek et al. (2003). The TM5 version used in this study differs in important aspects from the version used by van den Broek et al. First, in their study the advection scheme 
contained only first-order moments or slopes (Russel and Lerner, 1981). In this study also second-order moments advection (Prather, 1986) is applied.

The second crucial difference is the introduction of adjustable advection time steps when the CFL criterion is violated. This update avoids grid cell averaging in the polar regions. In all our previous model studies mass flux or grid cell averaging, referred to as "polar grid reduction" (labeled as "red. grid" in Table 1) was necessary in the stratosphere since the model did not contain iterative advection. See Sect. 2.3 in Krol et al. (2005) for a detailed description of the reduced grid treatment in TM5. In van den Broek et al. (2003) the reduced polar grid is illustrated within the zoom grid in Fig. 1 of that paper. Grid cell averaging was performed over the longitude for each polar latitude down to $70^{\circ} \mathrm{N}$. For numerical stability the pole cap remains one grid cell.

The third difference involves the possibility to apply time interpolation between the meteorology update intervals and the use of 3-hourly meteorology.

The final difference involves the vertical resolution. In the previous model evaluation by van den Broek et al. (2003) 33 layers were applied from the original ECWMF 60-layer coordinate by reducing some layers in the upper stratosphere and lower troposphere. In this study we used 45 layers, including all stratospheric levels. We have performed sensitivity runs with passive $\mathrm{CH}_{4}$ and varied the number of vertical layers between 30 and 60 , but the differences in the lower stratosphere were negligible (not shown). This is in line with the findings from Strahan and Polansky (2006) who found differences mainly in the upper stratosphere and mesosphere.

Without iterative advection the reduction of the polar grid cannot be validated because of computational limits, since the advection time steps would not only become excessively small (i.e. a few minutes only), but they would also have to be applied over the whole model domain. The new advection algorithm allows sufficiently small advection time steps by means of an iteration procedure for the location where a CFL violation occurs, rather than by applying it over the whole grid. Whenever a CFL violation occurs, the required number of iterations is determined by reducing the mass fluxes accordingly until the violation is solved. Then the advection is performed with the required number of iterations.

At the location where the violation occurred, the iteration is performed differently, depending on the mass flux direction. Zonally: for every longitude at the specific latitude. Meridionally: for every latitude and longitude at the specific pressure level. Vertically: for all model grid cells. In practice the majority of violations occur in the zonal direction where the winds are the strongest.

The iteration procedure has extensively been tested for numerical errors by using idealized passive tracers, and the errors remained close to machine precision (not shown). This model update was crucial, since it not only allows integrations at higher model grid resolutions but also allows a proper examination of model grid resolution.
The default configuration of TM5 in this study includes a global horizontal resolution of $3^{\circ} \times 2^{\circ}$ (longitude $\times$ latitude), 45 vertical layers and a second-order moment advection scheme (Prather, 1986). It further applies instantaneous wind fields from the ECMWF operational analyses updated every $6 \mathrm{~h}$.

In addition to the default model configuration we included a computationally cheap but diffusive first-order advection scheme ("slopes") (Russel and Lerner, 1981) and applied a zoom grid with a horizontal resolution of $1^{\circ} \times 1^{\circ}$ between $30^{\circ}-90^{\circ} \mathrm{N}$, similar as in van den Broek et al. (2003) (see their Fig. 1). Note that with the current model configuration, integrations including a zoom area could only be performed with the first-order advection scheme. This is because a secondorder moments advection introduces additional communication between the different zoom regions and requires fundamental changes in the model transport modules which were not feasible to perform.

For the trajectory experiment the trajectory model is used as described by Scheele et al. (2005).

\section{Experimental set-up}

This study contains a variety of model experiments including the CTM and the trajectory model. A summary of the model experiments with the main features including the diagnostics is given in Table 1 . The model evaluation covers two important regions: the Arctic polar vortex and the tropical stratosphere and three different diagnostics: passive $\mathrm{CH}_{4}$ tracer integrations, mean age of air calculations and air parcel dispersion. The experimental setup for the different diagnostics is given below.

\subsection{Passive $\mathrm{CH}_{4}$}

This CTM diagnostic covers the Arctic region and uses $\mathrm{CH}_{4}$ as a passive tracer. The model was integrated from September 1999 to April 2000. The experimental setup, including the model constraints, is similar as in van den Broek et al. (2003), which we summarize below.

Initialization is based on zonally averaged observations of August and September 1999, obtained from the HALOE 10 (HALogen Occultation Experiment) instrument aboard UARS (Upper Atmospheric Research Satellite) (Russel-III et al., 1993). In regions for which observations are not available (at the poles, in the troposphere and in a gap in the HALOE data between $43^{\circ} \mathrm{N}$ and $62^{\circ} \mathrm{N}$ ), the initial concentrations are linearly inter- or extrapolated from nearby latitudes and/or altitudes.

The $\mathrm{CH}_{4}$, concentrations in the lowest model layer are fixed at 1.76 ppmv. In the top two levels $\mathrm{CH}_{4}$ is constrained with HALOE observations (Randel et al., 1998), since chemical destruction of $\mathrm{CH}_{4}$ is not included in the model. Sensitivity runs carried out by van Aalst et al. (2004) show 
Table 1. A summary of the model experiments. See text for more details for each experiment.

\begin{tabular}{|c|c|c|c|c|}
\hline Experiment & advection & horizontal resolution & winds & diagnose \\
\hline "6hrly inst." & 2nd moments & $3^{\circ} \times 2^{\circ}$ & 6-hourly instantaneous "OD" & $\mathrm{CH}_{4}$, Mean age of air \\
\hline "6hrly inst. red. grid" & 2nd moments & $3^{\circ} \times 2^{\circ}$ & 6-hourly instantaneous "OD" & $\mathrm{CH}_{4}$ \\
\hline " $3 \times 2$-slopes red. grid" & 1st moments & $3^{\circ} \times 2^{\circ}$ & 6-hourly instantaneous “OD” & $\mathrm{CH}_{4}$, Mean age of air \\
\hline "3×2-slopes" & 1st moments & $3^{\circ} \times 2^{\circ}$ & 6-hourly instantaneous "OD” & Mean age of air \\
\hline "1×1-slopes" & 1st moments & $1^{\circ} \times 1^{\circ}$ & 6-hourly instantaneous "OD” & $\mathrm{CH}_{4}$, Mean age of air \\
\hline "6hrly interp." & 2nd moments & $3^{\circ} \times 2^{\circ}$ & 6-hourly interpolated “OD” & $\mathrm{CH}_{4}$, Mean age of air, Dispersion \\
\hline "3hrly interp." & 2nd moments & $3^{\circ} \times 2^{\circ}$ & 3-hourly interpolated “OD” & $\mathrm{CH}_{4}$, Mean age of air, Dispersion \\
\hline "6hrly interp. ERA40" & 2nd moments & $3^{\circ} \times 2^{\circ}$ & 6-hourly interpolated "ERA40" & Dispersion \\
\hline "3hrly interp. ERA40" & 2nd moments & $3^{\circ} \times 2^{\circ}$ & 3-hourly interpolated "ERA40" & Dispersion \\
\hline
\end{tabular}

that prescribing the top boundary concentrations have only a small or negligible effect on the tracer fields for the considered integration period. In addition, they found that ignoring chemical destruction of $\mathrm{CH}_{4}$ causes a small deviation of less than $10 \%$, and only above $10 \mathrm{hPa}$.

The observations were obtained from the balloon-borne Tunable Diode Laser Absorption Spectrometer (TDLAS) (Garcelon et al., 2002), the Jet Propulsion Laboratory MkIV interferometer (Toon et al., 1999), and the spaceborne HAlogen Occultation Experiment (HALOE) (RusselIII et al., 1993) on board the UARS satellite. The balloonborne observations were performed in the frame of the combined projects THird European Stratospheric Experiment on Ozone (THESEO) and Sage III Ozone Loss and Validation Experiment (SOLVE).

This diagnostic focuses on the high latitudes, since methane is treated as a passive tracer. For this reason the integration period is not more than half a year, but is sufficient for the purpose of this experiment. However, caution must be taken for mid-latitudes in the middle and upper stratosphere where the impact of chemistry becomes more pronounced.

\subsection{Mean age of air}

The mean age of air is calculated by applying the "tracer pulse" method, as described in Hall and Plumb (1994) and Hall et al. (1999). The tracer pulse method consists of an inert tracer released in the tropical troposphere with unity mass mixing ratio by applying a delta-function. The tracer is released in a latitude band between $10^{\circ} \mathrm{S}$ and $10^{\circ} \mathrm{N}$ and up to $200 \mathrm{hPa}$ during the first model step and set to zero afterwards (Meijer et al., 2004). The released tracer is transported to the stratosphere and the tracer mixing ratios in the stratosphere are a measure of the mean residence time, calculated using the Green function (Hall and Plumb, 1994). The year 2000 is integrated repetitively for 20 years. The mean age is calculated as the first moment of the derived spectrum after 20 years.

\subsection{Air parcel dispersion}

Using the same experimental setup as in Scheele et al. (2005) we examined the dispersion of air parcels in the tropical lower stratosphere by calculating 50-day back trajectories similar to the experiments performed by Schoeberl et al. (2002). We used January and February 2000 meteorology. Approximately 10000 trajectories started between $10^{\circ} \mathrm{S}-$ $10^{\circ} \mathrm{N}$ at $460 \mathrm{~K}$ potential temperature level, corresponding to a pressure of $50 \mathrm{hPa}$ or approximately $20 \mathrm{~km}$ altitude. As a measure of dispersion, the fraction of air parcels is calculated crossing the tropopause irriversibly. The tropopause is defined on basis of potential vorticity and close to the equator as the $380 \mathrm{~K}$ potential temperature level (Scheele et al., 2005). In this diagnose we have applied ECWMF 6-hourly interpolated operational analyses and 6-hourly and 3-hourly interpolated ERA40 re-analyses (see Table 1).

\section{Results}

\subsection{Passive $\mathrm{CH}_{4}$}

4.1.1 Comparison with balloon-borne profiles inside the polar vortex

We show a series of figures with comparisons of calculated by the CTM and observed $\mathrm{CH}_{4}$ profiles. The observations consist of single balloon- and space-borne profiles sampled in the polar vortex from December 1999 to April 2000 from Kiruna $\left(67.8^{\circ} \mathrm{N}, 20.4^{\circ} \mathrm{E}\right)$. The selected balloon profiles were all inside the polar vortex and represent the evolution of the tracer profiles during the winter. The reason for this selection is because in one of our previous model evaluation (van den Broek et al., 2003) the largest model overestimation was found for these profiles.

Figure 1 shows a comparison with observations for the CTM experiments "6hrly inst", "6hrly inst red. grid", "3×2slopes red. grid", and " $1 \times 1$-slopes" (see Table 1 for an overview of the model experiments). The model profiles 
OBSERVATIONS 6HRLY INST

3X2-SLOPES

6HRLY INST RED. GRID

$1 \times 1-$ SLOPES
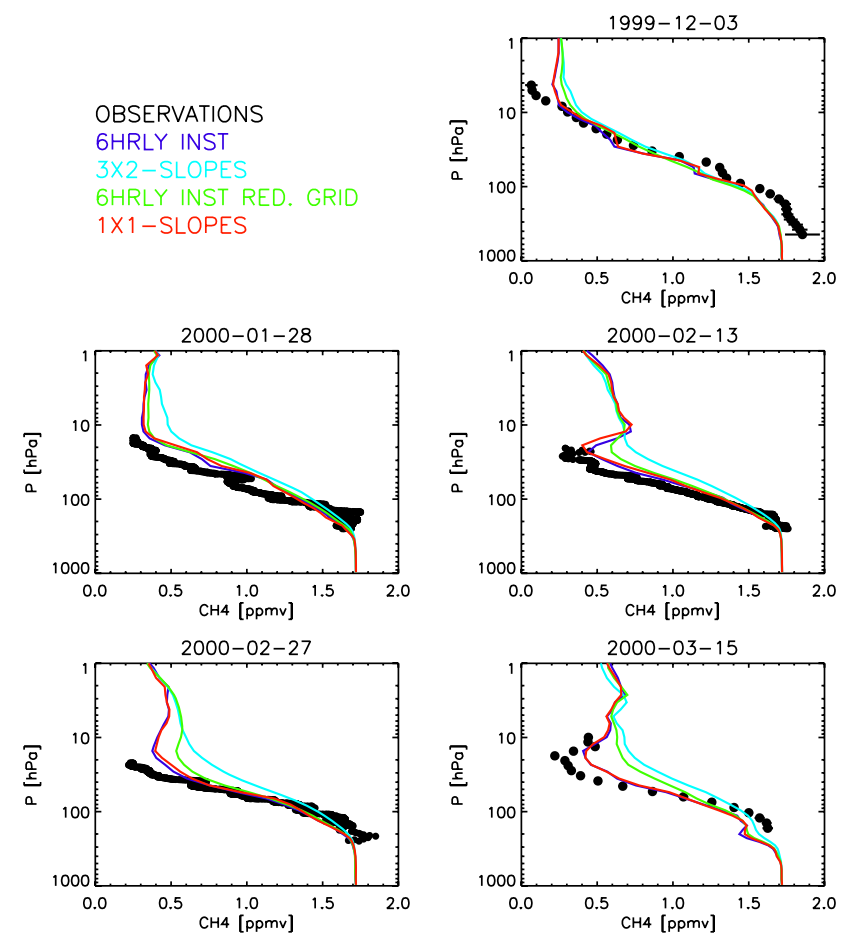

Fig. 1. Instantaneous methane profiles (ppmv) versus pressure (hPa), observed (black dots), and calculated by the model (solid lines) at 15 March 2000. The horizontal bars denote the 2- $\sigma$ observational uncertainty. The color lines represent the calculated profiles from the different model experiments.

were calculated for the location of the balloon launch with bi-linear interpolation using the adjacent grid cells. Different interpolation methods did not change the profiles (not shown). The observed decrease with altitude of $\mathrm{CH}_{4}$ profiles in Fig. 1 become stronger during the winter, reflecting the descent of the polar vortex air. In December the model results are close to the observations. However, the model overestimates $\mathrm{CH}_{4}$ later in the winter and the overestimation increases in time. For clarity we have added the " $3 \times 2$-slopes red. grid" results from van den Broek et al. (2003) which considerably overestimate the observed $\mathrm{CH}_{4}$ profiles. When applying the less diffusive second-order moments advection the overestimation reduces significantly and clearly shows the large sensitivity of tracer transport towards diffusive advection. This is even better illustrated when examining the results from the " $1 \times 1$-slopes" experiment. The diffusivity of the first-order advection reduces considerably when increasing the horizontal resolution to $1^{\circ} \times 1^{\circ}$. Now the results are very similar to the profiles calculated by the "6hrly inst." experiment.

Nevertheless the model still overestimates the tracer concentrations. The results from the "6hrly inst red. grid" experiment reflects the effect of the reduced polar grid. Although this experiment is performed with the less diffusive secondorder moments advection, the calculated profiles are signif-
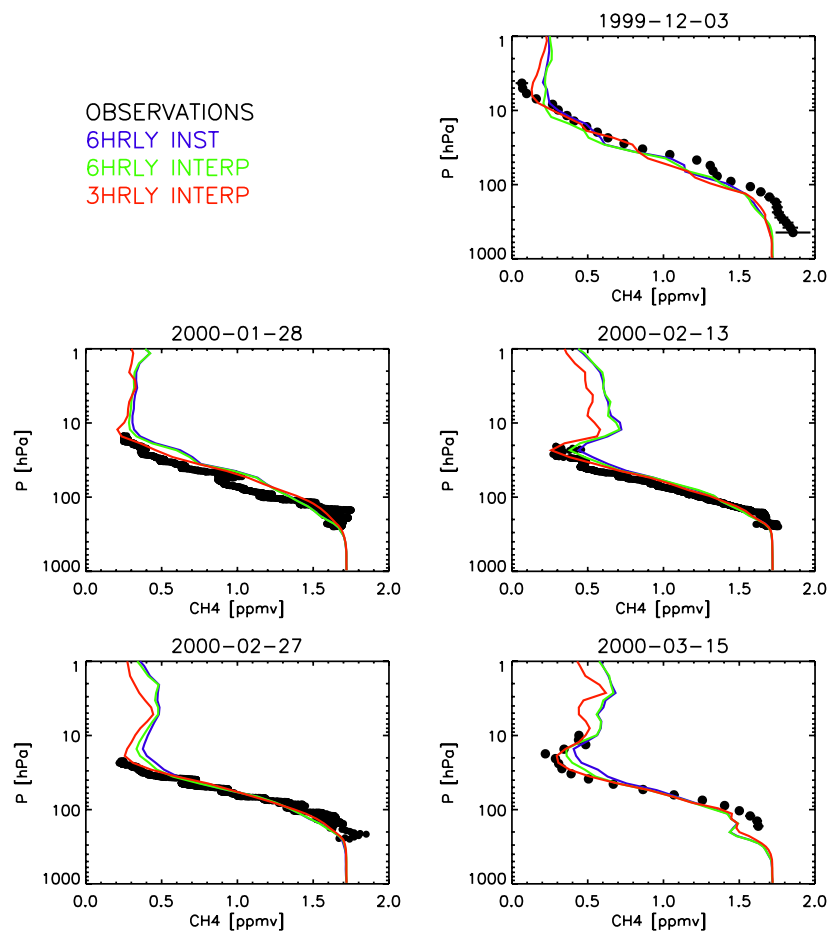

Fig. 2. As Fig. 1, but with the results from the model experiments applying interpolated winds and increased meteorology update frequency.

icantly overestimated and the discrepancy increases in time. This quite dramatic effect clearly shows the large sensitivity towards horizontal resolution.

The improvement when removing the reduced polar grid gives an important message to those who apply some kind of grid or mass flux or wind vector merging in the polar region. Another obvious message is that a reduction of the polar grid obscures evaluation of grid resolution. In van den Broek et al. (2003) their " $1 \times 1$-slopes" experiment did not improve the calculated $\mathrm{CH}_{4}$ profiles because that model version still contained the same polar grid averaging as in the coarser resolution setup.

Finally, we examined the effect of time interpolation and wind update frequency. Figure 2 shows the calculated $\mathrm{CH}_{4}$ profiles from the experiments "6hrly inst", "6hrly interp" and "3hrly interp". By interpolating the winds between two subsequent time intervals we account for the wind variability within the model integration time interval. The agreement with observations improves, especially on 15 March 2000. Applying 3-hourly interpolated winds the results are in excellent agreement with the observations.

\subsubsection{Horizontal cross sections in the polar region}

Figures 1 and 2 show that the model errors accumulate in time during the winter. Subsequently, the profile at the end of the winter on 15 March 2000 is quite interesting, since for 


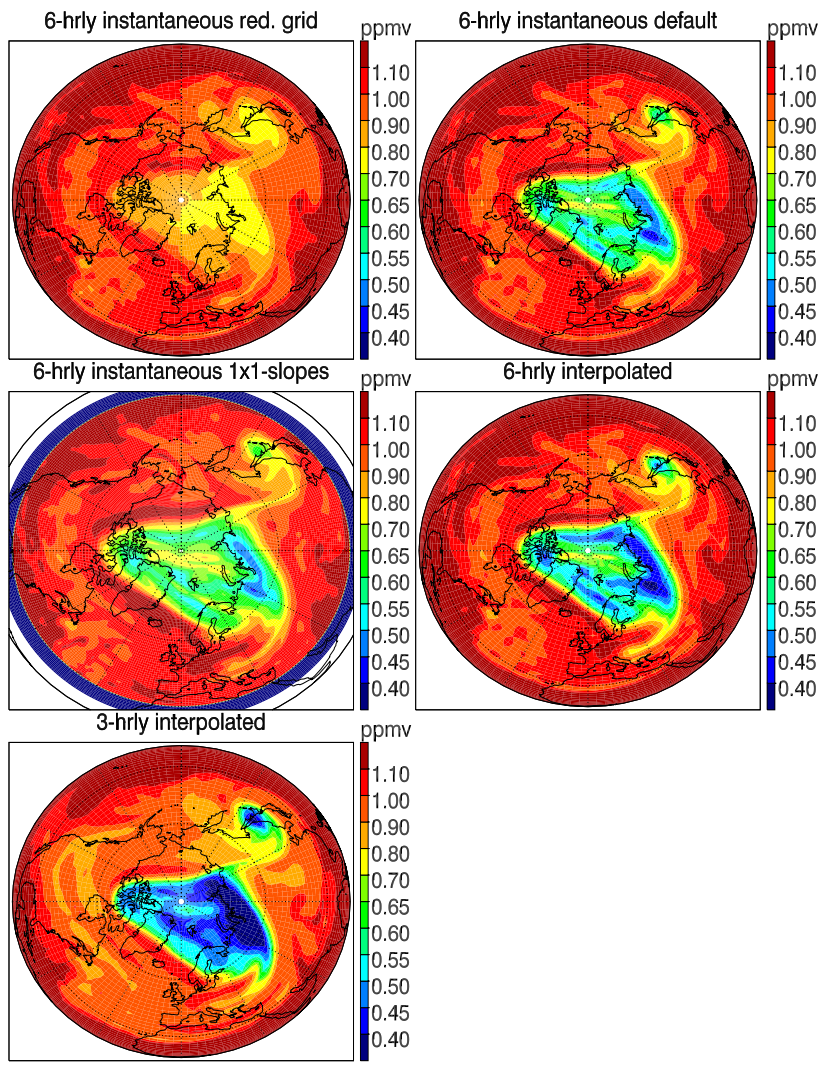

Fig. 3. Horizontal cross sections of methane mixing ratios (ppmv) at $35 \mathrm{hPa}, 15 \mathrm{March}$ 2000, 00:00 GMT for five different TM5 experiments.

this day the model discrepancies are most visible and the vortex was still very strongly developed, as was demonstrated in previous model intercomparison (van den Broek et al., 2003). Therefore we focus on this day and examined the polar vortex with horizontal cross sections of $\mathrm{CH}_{4}$ at $35 \mathrm{hPa}$.

Figure 3 shows the results for the "6hrly inst.", "6hrly inst. red grid", and " $1 \times 1$-slopes" experiments all using 6hourly instantaneous winds, and for the experiments with 6hourly and 3-hourly interpolated winds. $\mathrm{The} \mathrm{CH}_{4}$ levels from the reduced grid run are clearly higher with a very weak vortex edge and little tracer variability compared to the fields from the other experiments. The " 6 hrly inst." and the " $1 \times 1$ slopes" runs yield much stronger vortex edges and more variability and both fields are quite comparable. The vortex edge tracer gradients will be shown in more detail in Figs. 5, 6 and 7. The vortex gradients become slightly stronger when using 6-hourly interpolated winds, but significantly stronger when using 3-hourly interpolated winds. Note that also outside the vortex the tracer fields are considerably lower in this model version, indicating that applying time interpolation and in particular increasing the update frequency affect the tracer distribution on a large (hemispheric) scale. Berthet et al. (2006) also shows reduction in $\mathrm{N}_{2} \mathrm{O}, \mathrm{HNO}_{3}$ and $\mathrm{NO}_{2}$ in

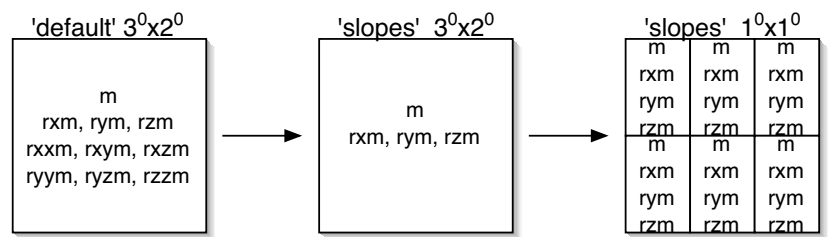

Fig. 4. A schematic view of the tracer information per grid cell of $3^{\circ} \times 2^{\circ}$, when applying second-moments (left) and first-order advection without grid zooming (middle) and with grid zooming (right).

the mid-latitude middle stratosphere when applying 3-hourly winds compared to 6-hourly winds.

\subsubsection{Diffusivity and model grid resolution}

The strong sensitivity of tracer advection to diffusivity is interesting, as shown by the results from the " $1 \times 1$-slopes" experiment. Numerical diffusion depends on the amount of tracer information for a given grid cell volume. Figure 4 shows the tracer information for a $3^{\circ} \times 2^{\circ}$ grid cell in the case of the default "6-hourly inst" experiment (left panel), the " $3 \times 2$-slopes" experiment (middle panel) and the " $1 \times 1$ slopes" experiment (right panel). The "6-hourly inst" experiment contains 10 parameters that determine the tracer level: the first-order slopes (3), the second-order moments (6), and the tracer mass (1). In contrast, the " $3 \times 2$-slopes" experiment only contains 4 variables with tracer information: the first-order slopes (3) and the tracer mass (1). On the other hand, the zoom region (" $1 \times 1$-slopes" experiment) contains 6 more grid cells with each 4 tracer parameters, resulting in a total of 24 on basis of a $3^{\circ} \times 2^{\circ}$ grid cell. The " $3 \times 2$-slopes" experiment contains the least amount of tracer information and clearly yields the worst results. However, the amount of tracer information in the " $1 \times 1$-slopes" experiment is twice more than that of the "6-hourly inst" configuration for a $3^{\circ} \times 2^{\circ}$ grid cell, but shows no improvement in the tracer distribution. This insensitivity to grid resolution supports the findings by Searle et al. (1998) although it depends on the diffusivity of the tracer advection. A diffusive advection scheme clearly overrules the advantage of resolution increase, at least up to $1^{\circ} \times 1^{\circ}$. It will also depend on the chemical lifetime of the tracer in question and for a relatively short-lived species such as $\mathrm{ClO}$ the impact of resolution increase may be substantial (Marchand et al., 2003; Tan et al., 1998).

\subsubsection{Comparison with satellite observations: tracer gradi- ent across the vortex edge}

Next, we focus on the tracer gradient through the vortex edge. A comparison is performed with 15 profiles observed by the HALOE instrument on board the UARS satellite. See van den Broek et al. (2003) for a more detailed description of these observations. These profiles were part of the HALOE 

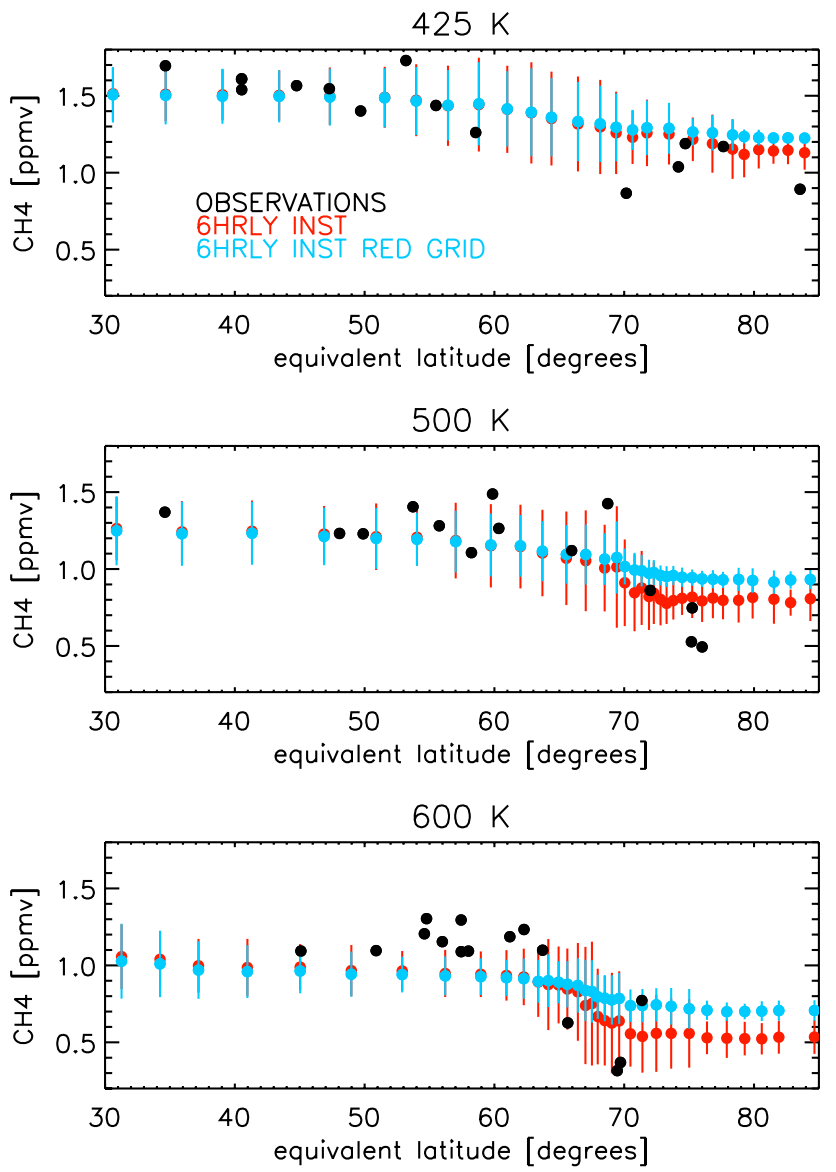

Fig. 5. Observed methane profiles volume mixing ratios in ppmv (black dots) at 15 March 2000, 00:00 GMT, and calculated by the model using 6-hourly instantaneous winds, "6hrly inst". (red dots) and the model run without the reduced polar grid, "6hrly inst. red. grid". The comparison is performed at equivalent latitude (degrees) and three different isentropic levels $(425 \mathrm{~K}, 500 \mathrm{~K}$, and $600 \mathrm{~K}$ ). The vertical bars represent $2 \sigma$ variability of the model results.

sweeps close to the edge of the polar vortex, covering both mid-latitudinal extra- and polar vortex air, and are thus very suitable to focus on the vortex edge. For such a comparison an equivalent, instead of the regular Cartesian, latitude coordinate is more useful. Three different potential temperature levels have been selected, one close to the polar vortex bottom $(425 \mathrm{~K})$, one in the lower stratosphere $(500 \mathrm{~K})$ and one in the middle stratosphere $(600 \mathrm{~K})$.

Figures 5, 6 and 7 show the results of this comparison for different CTM experiments. Each equivalent latitude contains several model values and each point represents the mean model value and the vertical bars represent the variability as $1 \sigma$. Each of these figures contains the results from the "6hrly inst" experiment compared with the results from another experiment. The reason is to allow a clear comparison of the different model versions with the default model ver-
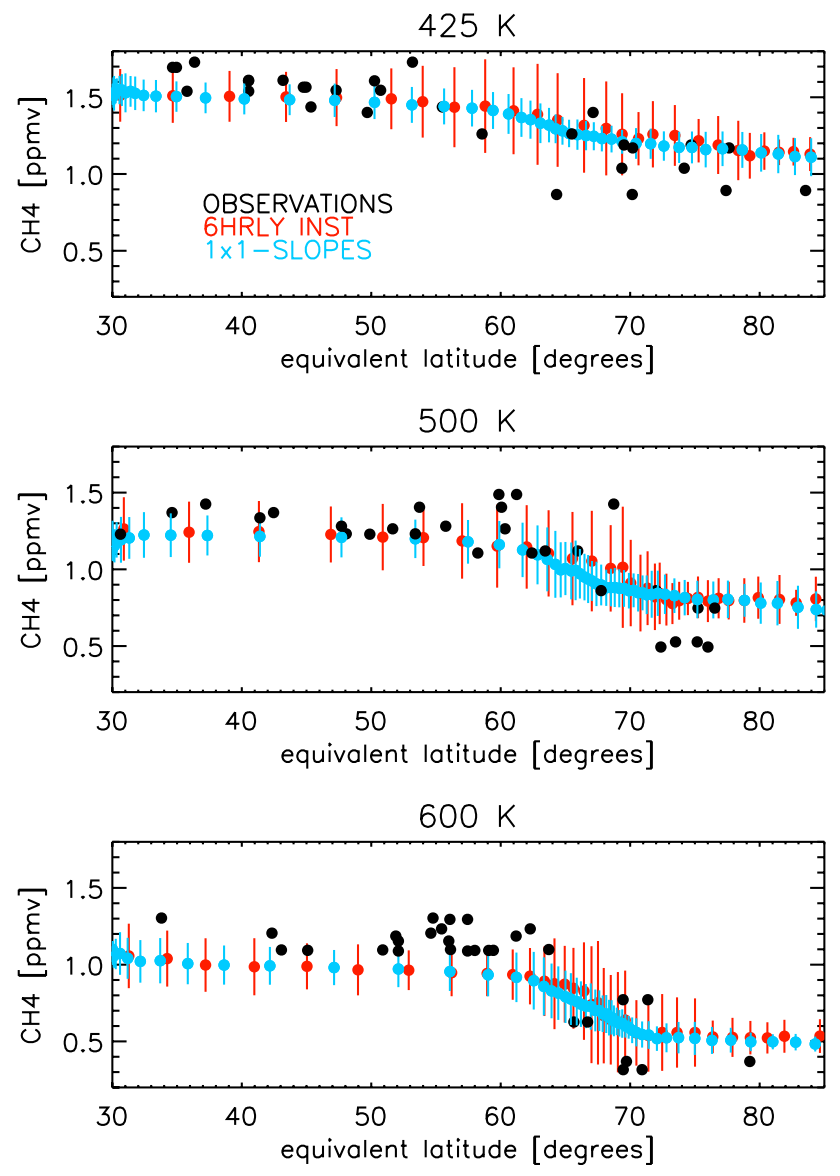

Fig. 6. Similar as Fig. 5, but with the results from the experiments "6-hourly inst." (red dots) and "1×1-slopes" (blue dots).

sion. For clarity we left out the "6hrly interp." experiment, since the results are very similar to those from the "6hrly inst" experiment.

The comparisons are somewhat obscured by the relatively large scatter in the observations, the limited coverage in the polar vortex and the modeled variability. The scatter in the observations is most probably due to the differences in the sampling volume of the observations and the ECWMF potential temperature and potential vorticity grid cell volumes. Nevertheless, the latitudinal coverage is sufficient and the tracer gradient and variability across the vortex edge are clearly discernible. As expected, the gradient becomes more pronounced with increasing potential temperature level, both in the observations and in the model results. The results from the "6hrly inst" experiment agrees quite reasonable with the observations, while significant underestimation is found when applying polar grid averaging ("6hrly inst red. grid"), in line with the findings in Fig. 1. The tracer gradient at the vortex edge is manifested most clearly in the " $1 \times 1$-slopes" experiment, although the overall gradient is similar to the default run. 

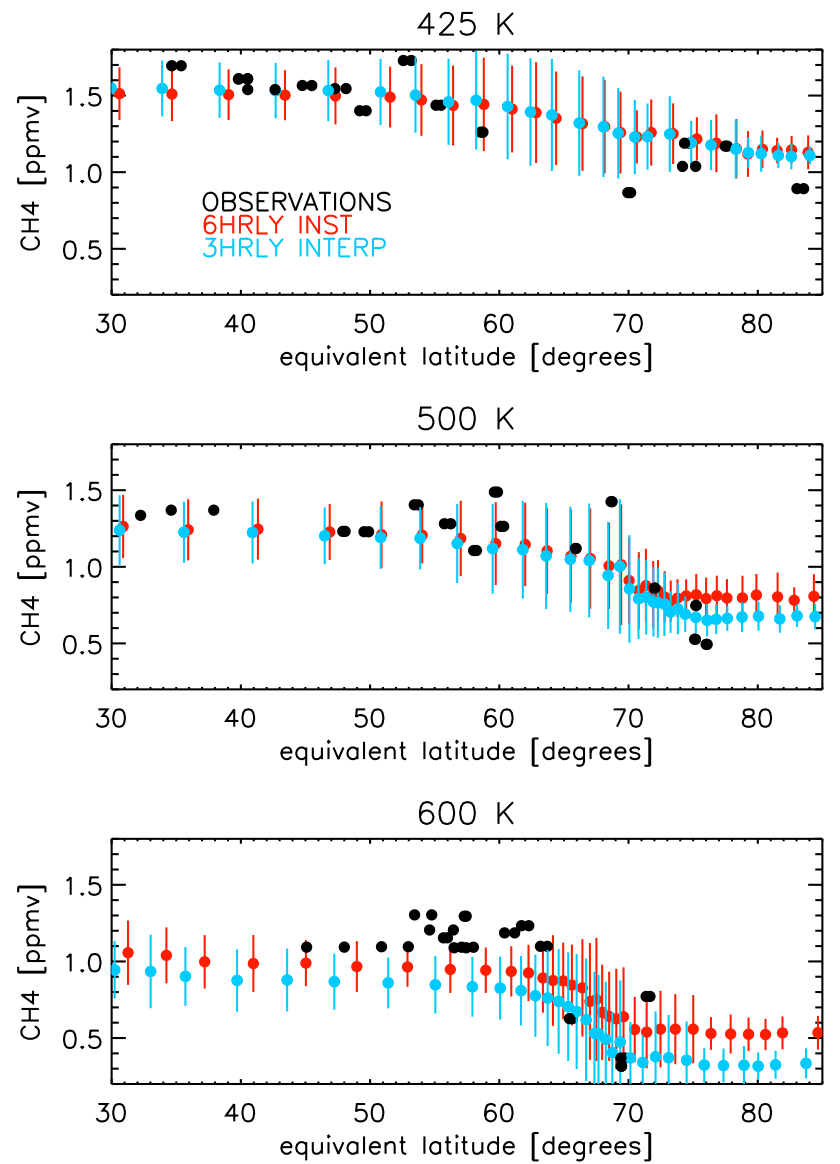

Fig. 7. Similar as Fig. 5, but with the results from the experiments "6-hourly inst." (blue dots) and "3-hourly interp" (red dots).

It is interesting that the modeled variability is significantly reduced in " $1 \times 1$-slopes" experiment, especially in active mixing regions: close to the vortex bottom and at the vortex edge. This reflects the increased tracer information in the zoom region, despite the more diffusive advection scheme (see Fig. 4).

As can be seen in Fig. 7 the calculated gradients became stronger when introducing time interpolation and in particular by increasing the meteorological update frequency, in line with the model results described earlier. The differences with the results from the default ("6hrly inst") experiment increase with increasing potential temperature level. At $600 \mathrm{~K}$ the model underestimates the observations at $50-60^{\circ} \mathrm{N}$ outside the polar vortex, which is apparent in the results from all model experiments. It is also interesting that the variability of the "3hrly interp" experiment is similar to that calculated by the "6hrly inst" experiment. Since the variability calculated by the " $1 \times 1$-slopes" experiment is much less one may expect a stronger vortex edge gradient. However, this is not the case, as can clearly be seen in Fig. 3 .

Note that even in the best model performance the calculated gradient is slightly underestimated, indicating remain-

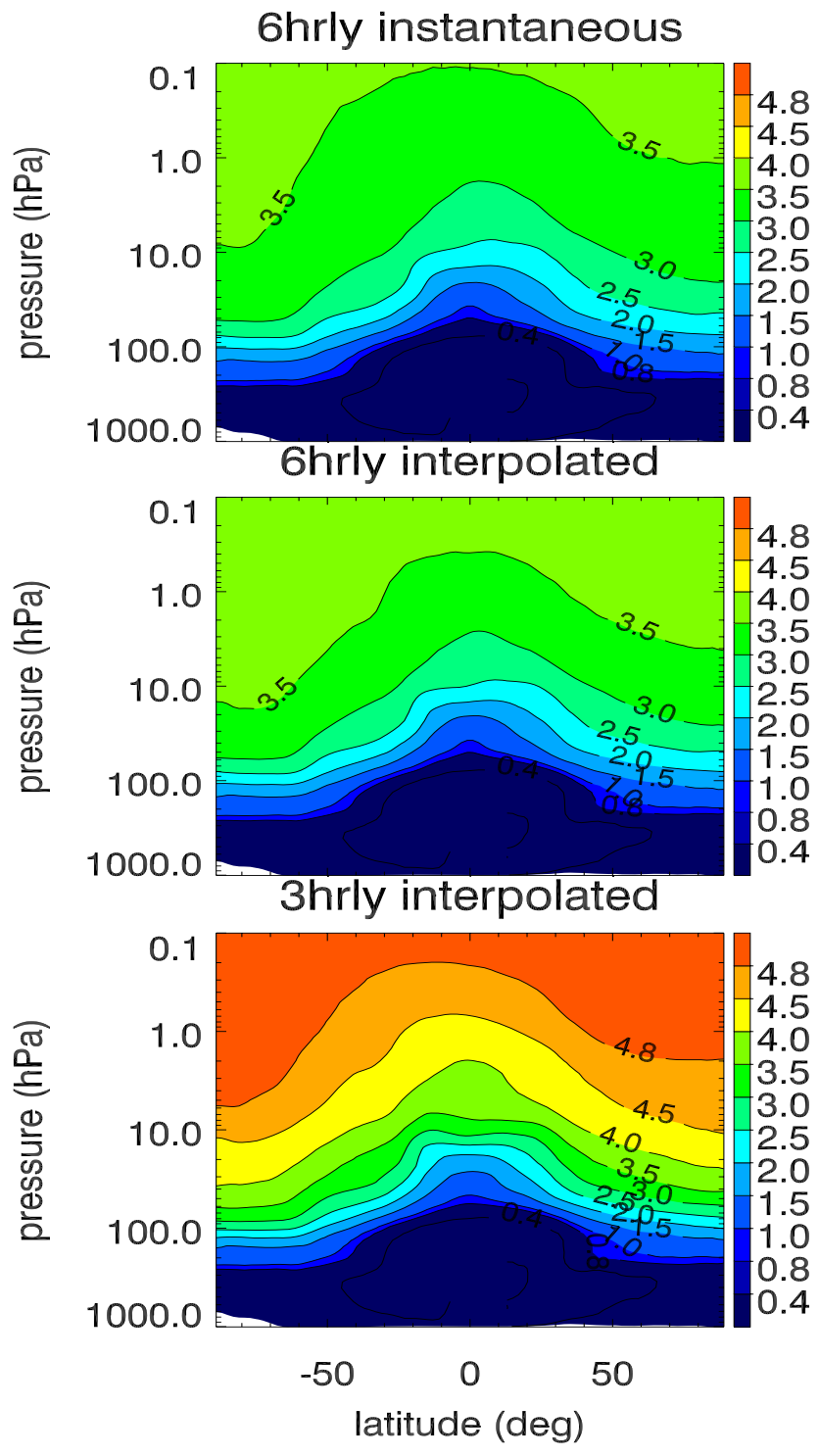

Fig. 8. Calculated latitudinal cross section of zonally average mean age of air (years) for three different experiments: 6-hourly instantaneous (top panel), 6-hourly interpolated (middle panel) and the 3-hourly interpolated winds (bottom panel), respectively.

ing diffusivity and/or the lack of chemistry. Although the effect of chemistry has been tested to have a negligible impact on methane at levels below $10 \mathrm{hPa}$ in a similar model experiment (van Aalst et al., 2004), caution must be taken by treating methane as a passive tracer. Especially close to more chemically active regions of the atmosphere, i.e., the upper stratosphere outside the polar vortex. Indicative for this influence could be the slight underestimation by the model in Fig. 6 and 7 at the highest potential temperature level $(600 \mathrm{~K})$. 


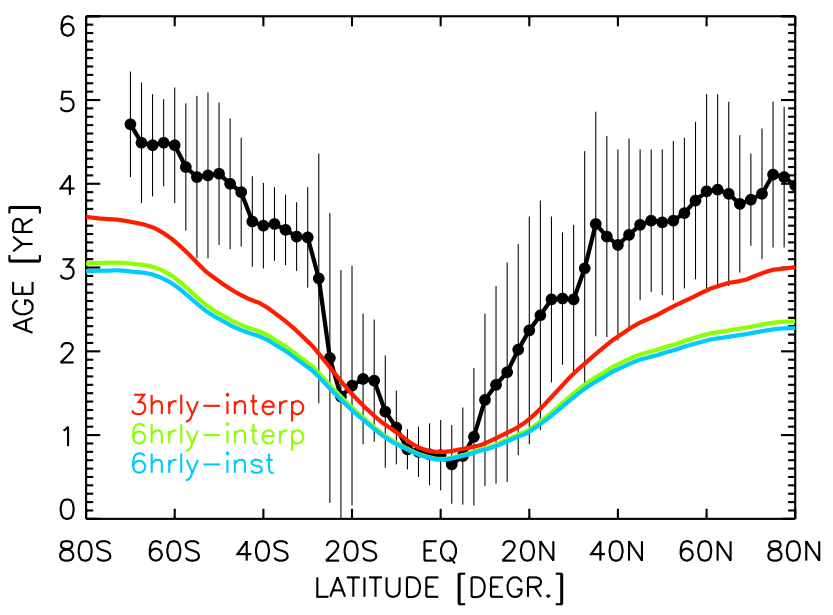

Fig. 9. Observed and calculated mean age of air for the same experiments as in Fig. 8. The observations (black dots) are derived from multi-year $\mathrm{CO}_{2}$ observations from the ER-2 at approximately $20 \mathrm{~km}$ altitude (Andrews et al., 2001). The error bars represent 2- $\sigma$ standard deviation.

\subsection{Mean age of air experiment}

In this diagnose we evaluate the large-scale meridional circulation in the stratosphere by calculating the mean age of air, as described in the experimental setup section. Recently our group has performed this diagnose for a variety of model versions, including CTM and trajectory calculations (Bregman et al., 2003; Meijer et al., 2004; Scheele et al., 2005). All these CTM calculations were performed including polar grid averaging and some of these experiments also included first-order advection. Meijer et al. (2004) found that applying first-order advection has negligible impact on the mean age of air. We have performed an additional mean age of air calculation for the " $1 \times 1$ slopes" experiment to examine the effect of grid resolution on the mean age. Since this diagnostic covers both hemispheres we were forced to use a global $1^{\circ} \times 1^{\circ}$ grid instead of a zoom region.

None of the model experiments have sofar examined the effect of time interpolation and update frequency of the winds on the mean age of air. Figure 8 shows the calculated zonally average mean age of air for the CTM experiments "6hrly inst" (top panel), "6hrly interp" (middle panel) and "3hrly interp" (bottom panel). The maximum mean age calculated by the "6hrly inst" experiment is around 3.5 years, which is significantly too young acocording to observations. This finding is in line with the conclusions in previous studies that the meridional circulation is too fast for assimilated winds leading to too short stratospheric residence times of the air parcels (Schoeberl et al., 2002; Meijer et al., 2004; Douglass et al., 2003).

When applying time interpolation ("6hrly interp") the results improve marginally in the lower stratosphere, in agreement with the results from the $\mathrm{CH}_{4}$ diagnose. The air be-

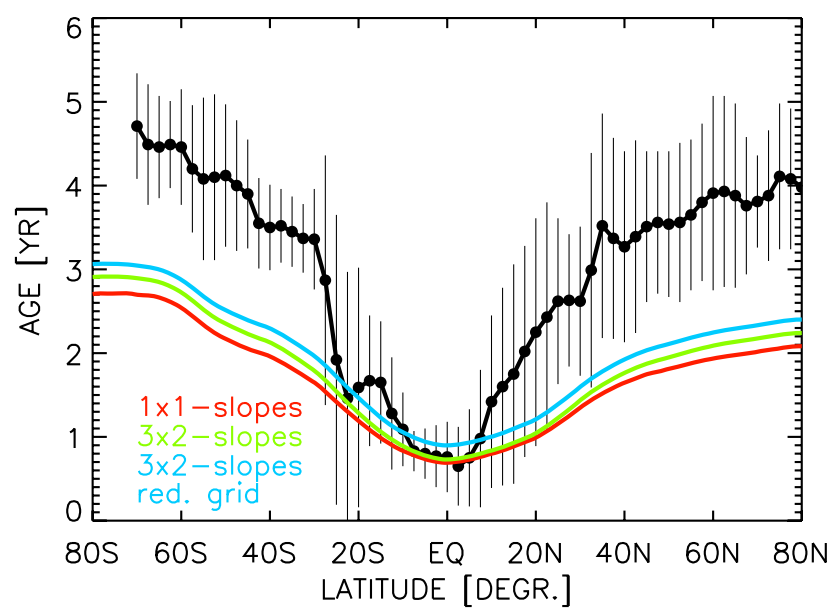

Fig. 10. Observed and calculated mean age of air for the experiments " $3 \times 2$-slopes", " $3 \times 2$-slopes red. grid", and " $1 \times 1$-slopes".

comes approximately 0.5 year older in the middle and upper stratosphere. However, the mean age of air is significantly older when using 3-hourly interpolated winds, with maximum a mean age in the upper stratosphere close to 5 years. This result shows that increasing the update frequency improves the tracer transport on a hemispheric scale considerably.

Figure 9 shows the calculated zonally average mean age of air for the same three runs compared to observations, but now at approximately $20 \mathrm{~km}$ altitude. For the evaluation of the modeled mean age of air we used a compilation of $\mathrm{CO}_{2}$ and $\mathrm{SF}_{6}$ observed on board the ER-2 between 1991-1998 (Andrews et al., 2001). The calculated mean age of air from the model experiments agrees well with the observations in the tropics, but shows an underestimation in the extra-tropics with maximum ages of 3-3.6 years at $20 \mathrm{~km}$ altitude. Note that the mean age from the "6hrly inst" experiment is similar to that calculated by Meijer et al. (2004) in their default model setup experiment.

In line with Fig. 8 the use of 3-hourly interpolated winds increases the mean age of air. The calculated meridional gradient of the mean age is significantly steeper than using 6hourly winds, indicative of reduced dispersion. Nevertheless the calculated mean age still remains about one year too young in the extra-tropical lower stratosphere. Applying time interpolation in the 6-hourly winds only yields a small improvement in the lower stratosphere.

Figure 10 shows the calculated zonally average mean age of air at $20 \mathrm{~km}$ altitude for three different experiments applying first-order (slopes) advection. For clarity we have added the results from the experiment " $3 \times 2$ slopes red. grid", which is similar as the one used by Meijer et al. (2004). As can be seen, all experiments give very similar results. We therefore have omitted the meridional cross-section fields. Although the calculated mean tropical ages are realistically 

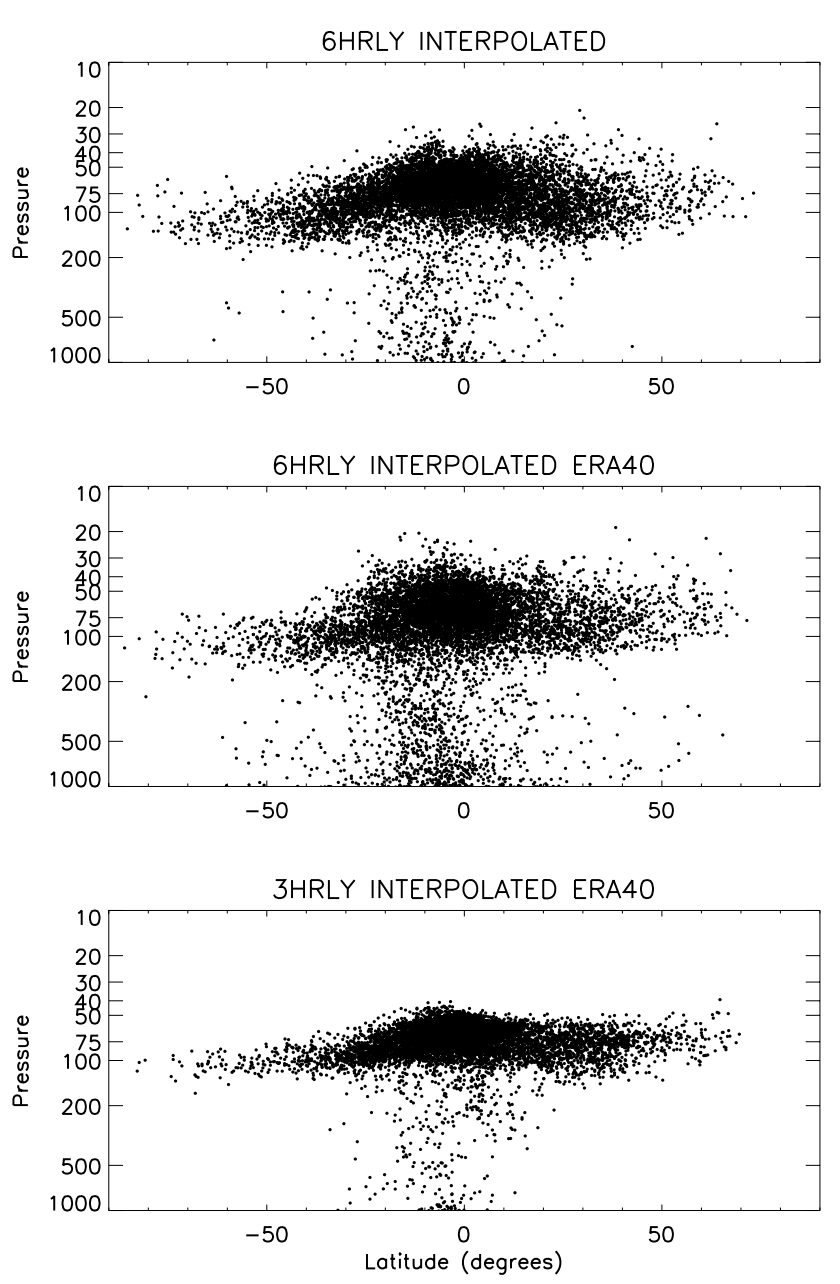

Fig. 11. The end locations of the air parcels after 50 days backtrajectory calculations using 6-hourly interpolated winds from the operational analyses (top panel), and using 6-hourly and 3-hourly interpolated winds from re-analyses data, ERA40 (middle and bottom panel).

represented, the extra-tropical mean age of air is significantly too young with maxima of only 3 years $(\mathrm{SH})$ and $2-2.5$ years $(\mathrm{NH})$. Consequently, the observed meridional gradient is underestimated.

There is negligible improvement when omitting the reduced polar grid and even when increasing the model horizontal grid resolution to $1^{\circ} \times 1^{\circ}$ degree. These results indicate little sensitivity of the mean age of air to grid resolution. This can be expected since the stratospheric tracer gradients are relatively small in these diagnostics, considerably reducing the advantage of more tracer information per grid volume. As pointed out by others (Hall et al., 1999; Waugh and Hall, 2002) the mean age of air diagnostics is designed to evaluate the quality of the winds.

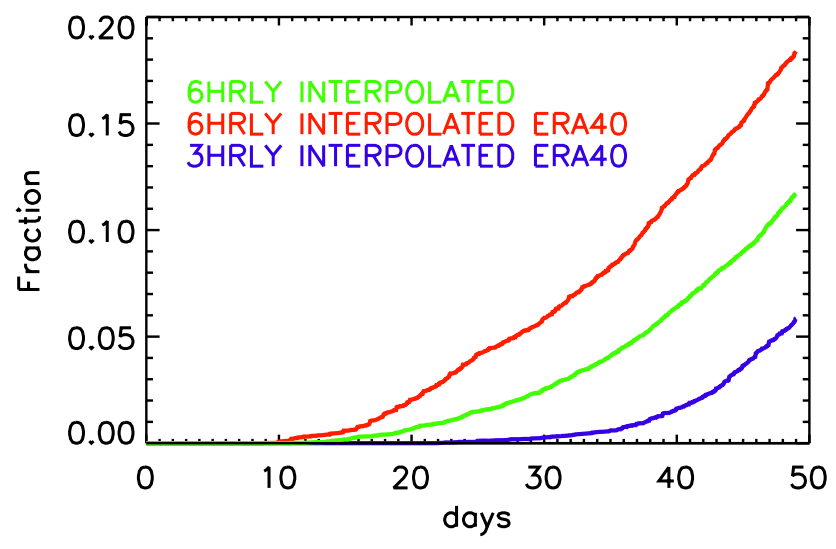

Fig. 12. The fraction of air parcels crossing the tropopause for the same experiments as in Fig. 11: 6-hourly interpolated winds from OD (green line), and 6-hourly (red line) and 3-hourly (blue line) interpolated winds from ERA40.

\subsection{Back-trajectory experiments}

Next we focus on the tropical lower stratosphere, since this is a key region for the large-scale meridional circulation. With back-trajectory calculations we calculate the dispersion of air parcels after 50 days. This time scale is much shorter than the mean age of air, but the dispersion intensity is a useful measure of the noise in DAS winds and thus indirectly relates to the mean age of air (Schoeberl et al., 2002; Scheele et al., 2005). So far we have illustrated that increasing the update frequency of the assimilated winds significantly improves the stratospheric tracer transport on a hemispheric scale. In this diagnose we examine the impact of update frequency for the 40-year re-analyses from the ECWMF (ERA40).

We examined 6-hourly and 3-hourly interpolated winds from ERA40. For comparison we added the 6-hourly interpolated winds from the operational analyses, corresponding to our "6hrly interp" experiment. Figure 11 shows the end points of the air parcels after 50 days. The "6hrly interp" winds are considerably dispersive both horizontally and vertically, similar to the results from Schoeberl et al. (2002) and clearly reflects the dispersive character of assimilated winds.

The middle panel shows that the ERA40 6-hourly interpolated winds lead to somewhat more dispersion. This is well known, since winds derived by 3DVAR assimilation are more dispersive than winds from the computationally more expensive 4DVAR assimilation (Scheele et al., 2005). However, the 3-hourly winds from ERA40 show much less vertical dispersion (lower panel in Fig. 11), even compared to the 6-hourly interpolated winds from the operational analyses. Interestingly, the horizontal dispersion is not reduced in the 3-hourly winds. In the next section we demonstrate that this may reflect real atmospheric motion rather than an indication of poor wind quality. 

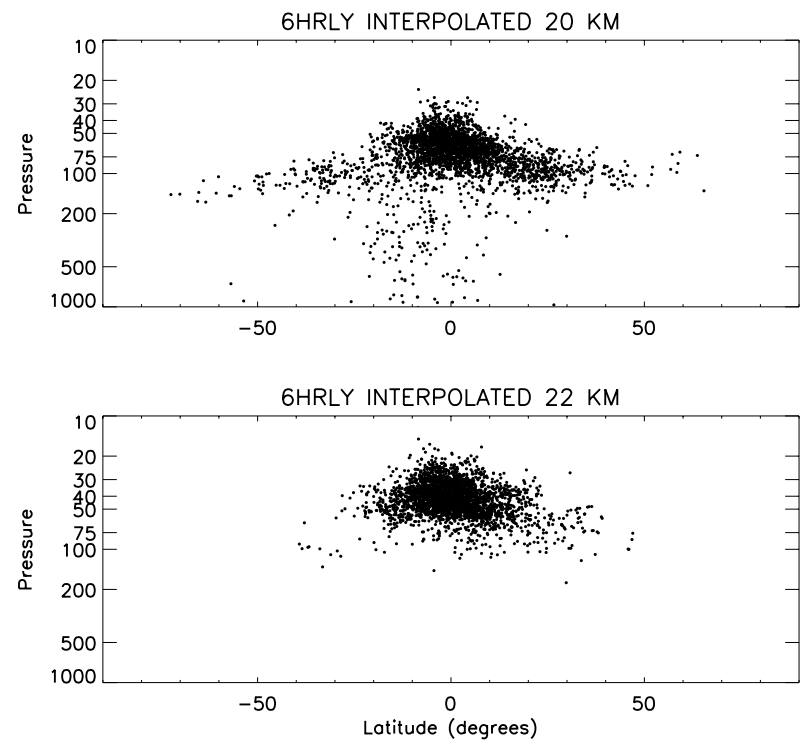

Fig. 13. The end locations of 2880 air parcels after 50 days backtrajectory calculations using 6-hourly interpolated winds from the operational analyses, similar as in Fig. 11, using a starting altitude at the equator at an altitude of $20 \mathrm{~km}$ (top panel) and $22 \mathrm{~km}$ (bottom panel).

Figure 12 shows the air parcel dispersion more quantitatively by the fraction of air parcels crossing the tropopause irriversibly. The larger the fraction, the more dispersive the winds. In line with Fig. 11, the 6-hourly interpolated winds from the operational analyses are less dispersive than the 6hourly winds from ERA40. This result is similar as in Fig. 2 in Scheele et al. (2005). But now adding the results from 3hourly ERA40 data yields a strong decrease of the fraction. It is even smaller than that calculated with the 6-hourly winds from the operational analyses.

\section{Discussion}

Particularly the use of 3-hourly winds results in improved stratospheric tracer distributions. It is important to note that the use of 3-hourly winds does not introduce more noise in an Eulerian frame as in most CTMs, but introduces more real variability in the wind fields. However, the most suitable update frequency for stratospheric tracer transport remains to be determined. This issue is directly related to the representation of the winds from the GCM that provides the winds to the data assimilation system. Waugh et al. (1997) discussed different time intervals, averaging and aliasing effects but not for time frequencies of $3 \mathrm{~h}$ or even less. Investigating this problem is however not trivial and is subject of further study.

Interestingly, the horizontal dispersion is not reduced when applying 3-hourly winds. Since the mean age of air in the tropical region is well represented, reducing the horizontal resolution would likely result in too old air. Although the amount of horizontal dispersion cannot be validated, useful information can be derived from observations of the aerosols after the eruption of Mount Pinatubo. Airborne differential absorption LIDAR observations reveal a well-mixed lower stratospheric layer in the tropics and subtropics (Grant et al., 1994). The altitude of that layer is about $20 \mathrm{~km}$ coinciding with the initial altitude of the back trajectory calculations. The observations indicate that this layer is only about 1 to 2 kilometers thick where above a strong meridional gradient is visible, representing the sub-tropical barrier. Hence, enhanced horizontal dispersion is not necessarily an indication of poor model wind quality, but may in contrast be real atmospheric transport.

To investigate this interpretation we performed an additional air parcel dispersion experiment where we increased the starting altitude with $2 \mathrm{~km}$ to see if the model winds would also lead to reduced horizontal dispersion as the observations indicate. We used the same 6-hourly winds from the operational analyses as in the top panel in Fig. 11 and started 2880 back-trajectories at the equator at 20 and $22 \mathrm{~km}$ altitude respectively. The results are shown in Fig. 13. The dispersion using a starting point at $20 \mathrm{~km}$ is similar as in Fig. 11 top panel albeit with less trajectories. Indeed, the dispersion in particular in the horizontal, but also in the vertical direction is strongly reduced when using $22 \mathrm{~km}$ as starting point.

This demonstrates that the dispersive character of DAS winds in the tropical region is very sensitive to altitude and that the calculated dispersion intensity follows the observed vertical structure of the sub-tropical barrier. The strong sensitivity of the dispersion to altitude right at the initial altitude of the trajectory calculations questions the experimental setup applied in this study to assess air parcel dispersion. Note that this experimental setup is similar as in e.g. Schoeberl et al. (2002) and is a generally accepted diagnose.

The representation of the large-scale meridional circulation in the stratosphere by DAS winds may considerably improve when using isentropic vertical coordinates and heating rates instead of vertical wind velocity or mass fluxes on pressure levels (Mahowald et al., 2002; Chipperfield, 2006). Although an isentropic coordinate seems physically more appropriate for stratospheric dynamics, a mass correction needs to be performed in order to balance the divergence with the isentropic tendencies, which will impact the tracer distributions. This is a fundamental mass balance problem that applies to both CTMs and GCMs independent of the vertical coordinate system, as has been demonstrated by Jöckel et al. (2001) and for which different mass fixers have been introduced (cf. Bregman et al., 2003; Rotman et al., 2004). When integrating over a full vertical range from the upper stratosphere to the surface, the isentropic vertical coordinate needs to be adjusted from purely isentropic to a hybrid of pressure and isentropes. So far only two models have inferred such a hybrid coordinate (Mahowald et al., 2002; Chipperfield, 2006), which still contain mass imbalance issues but are promising developments. 
Nevertheless, hybrid $\sigma$-pressure remains a practical vertical coordinate for global tracer modeling because of cloud presence. Radiative heating calculations are complicated in the vicinity of clouds, also aloft introducing additional uncertainty in vertical transport with isentropic coordinates.

\section{Conclusions}

In this study we used a 3-D CTM and a trajectory model to investigate the impact of a variety of different model configurations and different representations of the assimilated meteorology on stratospheric tracer transport. In particular we examined the impact of model grid resolution including the reduction of the polar grid, the diffusivity of the advection scheme, time interpolation and the update frequency of the applied assimilated winds. As diagnostics we used the CTM for $\mathrm{CH}_{4}$ transport in the Arctic polar vortex and the mean age of air, and the trajectory model for air parcel dispersion in the tropical lower stratosphere. The CTM used ECMWF operational data only, while the trajectory model used both operational data and the ECWMF 40-year re-analyses.

The sensitivity experiments demonstrated that at least second-order moments in the advection are required for stratospheric modeling, which is well known in the modeling community. However, a more diffusive (first-order) advection yield reasonable tracer distributions when increasing the horizontal resolution to $1^{\circ} \times 1^{\circ}$, which contrasts the conclusions from our previous model evaluation. The reason for this contrasting result is because in the previous model study a polar grid averaging was applied to avoid numerical problems, while in this study such averaging could be avoided through iterative advection.

This study thus demonstrates the danger of the commonly applied polar model grid averaging when evaluating model grid resolution and contains an important message for other global model studies on polar tracer transport. Iterative advection makes high resolution modeling feasible in the polar regions with a global CTM.

The impact of wind variability by time interpolation and in particular by increasing the update frequency affects the stratospheric $\mathrm{CH}_{4}$ distribution in the polar region. Using 6hourly time interpolated instead of instantaneous winds resulted in reduced cross vortex edge mixing and closer agreement with the observed $\mathrm{CH}_{4}$ profiles inside the Arctic polar vortex. Reducing the time interval to $3 \mathrm{~h}$ improves the model results even further and yield excellent agreement with the observed $\mathrm{CH}_{4}$ polar vortex profiles.

The stratospheric meridional circulation is examined by diagnosing the mean residence time (age) of air in the stratosphere. De default model version yields too young mean age of air, in agreement with previous model studies. This is a well known shortcoming of dispersive assimilated winds which enhance the stratospheric circulation. More interestingly is that both polar grid averaging and increased horizon- tal resolution have negligible impact on the mean age of air in contrast to the findings in the polar region. Apparently, the small stratospheric tracer gradients make this diagnose insensitive to the amount of tracer information per grid cell volume.

The mean age of air is more sensitive to wind variability. It becomes significantly older in the extra-tropical stratosphere when applying 3-hourly instead of 6-hourly interpolated winds. The mean age is less sensitive to time interpolation and is particularly noticeable in the middle and upper stratosphere where it becomes 0.5 year older compared to the default model experiment. The tropical mean age of air shows excellent agreement with observations, although the extra-tropical lower stratospheric mean age remains too young with about one year.

The back-trajectory experiments show that the 6-hourly reanalyses contains more dispersion than the 6-hourly operational analyses as is expected when applying 3DVAR assimilation. In line with the findings from the mean age of air diagnostic, the use of 3-hourly winds significantly reduces the vertical dispersion in the tropical lower stratosphere and the re-analyses data even contains less vertical dispersion than the winds produced by the 6-hourly interpolated operational analyses.

The horizontal dispersion in particular remains relatively strong, even when applying 3-hourly winds. However, it is important to note that strong horizontal transport is observed around $20 \mathrm{~km}$ altitude in the tropics and subtropics, so that calculated enhanced horizontal dispersion is not necessarily an indication of poor wind quality. Starting the back-trajectory calculations only $2 \mathrm{~km}$ higher the dispersion is considerably reduced, coinciding with the observed vertical structure of the sub-tropical barrier. Hence, the dispersion calculations using the current experimental setup should be interpreted with great care.

For models using vertical hybrid sigma-pressure coordinates recent new insights in the implementation of DAS winds in CTMs has improved the stratospheric tracer representation considerably, both in the polar region as on a hemispheric scale. It is recommended not to use a reduction of the polar grid (either through grid cell merging or by wind averaging). We also recommend applying time interpolation instead of using instantaneous winds. In line with the findings from Legras et al. (2005) it is also recommended to apply 3-hourly instead of the commonly used 6-hourly update interval. These results in combination with expected improvements in the data assimilation procedures give new perspectives for long-term tracer integrations using assimilated winds.

Acknowledgements. Part of this work is funded by the European Commission, through the project TOwards the Prediction of stratospheric OZone (TOPOZ) III, under contract no. EVK2-CT-200100102, the project Stratospheric-Climate Links with Emphasis on the Upper Troposphere and Lower Stratosphere (SCOUT), and the National (Netherlands) User Support Programme (GO)2. We 
thank M. Krol and A. Segers for computational support and useful discussions. We are also grateful to A. Stohl and one anonymous reviewer for their valuable comments.

Edited by: B. Kärcher

\section{References}

Andrews, A., Boering, K., Daube, B., Wofsy, S., Loewenstein, M., Jost, H., Podolske, J., Webster, C., Herman, R., Scott, D., Flesh, G., Moyer, E., Elkins, J., Dutton, G., Hurst, D., Moore, F., Ray, E., Romanshkin, P., and Strahan, S.: Mean ages of stratospheric air derived from in situ observations of $\mathrm{CO}_{2}, \mathrm{CH}_{4}$, and $\mathrm{N}_{2} \mathrm{O}$, $\mathrm{J}$. Geophys. Res., 106, 32 295-32 314, 2001.

Berthet, G., Huret, N., Lefévre, F., Moreau, G., Robert, C., Chartier, M., Catoire, V., Barret, B., Pisso, I., and Pomathiod, L.: On the ability of chemical transport models to simulate the vertical structure of the $\mathrm{N}_{2} \mathrm{O}, \mathrm{NO}_{2}$ and $\mathrm{HNO}_{3}$ species in the mid-latitude stratosphere, Atmos. Chem. Phys., 6, 1599-1609, 2006, http://www.atmos-chem-phys.net/6/1599/2006/.

Bregman, A., Krol, M., Teyssèdre, H., Norton, W., Chipperfield, M., Pitari, G., Sundet, J., and Lelieveld, J.: Chemistry-transport model comparison with ozone observations in the midlatitude lowermost stratosphere, J. Geophys. Res., 106, 17479-17496, 2001

Bregman, A., Wang, P.-H., and Lelieveld, J.: Chemical ozone loss in the tropopause region on subvisible ice clouds, calculated with a chemistry-transport model, J. Geophys. Res., 107, doi:10.1029/2001JD000761, 2002.

Bregman, B., Segers, A., Krol, M., Meijer, E., and van Velthoven, P.: On the use of mass-conserving wind fields in chemistrytransport models, Atmos. Chem. Phys., 3, 447-457, 2003, http://www.atmos-chem-phys.net/3/447/2003/.

Chipperfield, M.: New version of the TOMCAT/SLIMCAT off-line chemical transport model, Q. J. R. Meteorol. Soc., 132, 11791203, doi:10.1256/qj.05.51, 2006.

Dentener, F., Feichter, J., and Jeuken, A.: Simulation of the transport of $\mathrm{Rn}^{222}$ using on-line and off-line global models at different horizontal resolutions: A detailed comparison with measurements, Tellus, 51, 573-602, 1999.

Douglass, A., Schoeberl, M. R., Rood, R. B., and Pawson, S.: Evaluation of transport in the lower tropical stratosphere in a global chemistry and transport model, J. Geophys. Res., 108, 4259, doi:10.1029/2002JD002696, 2003.

Garcelon, S., Gardiner, T., Hansford, G., Harris, N., Howieson, I., Jones, R., McIntyre, J., Pyle, J., Robinson, J., Swann, N., and Woods, P.: Investigation of $\mathrm{CH}_{4}$ and $\mathrm{CFC}-11$ vertical profiels in the Arctic vortex during the SOLVE/THESEO 2000 campaign, in Proceedings of the general Assembly, Nice, European Geophyisical Society, 2002.

Grant, W., Browell, E., Fishman, J., Brackett, V., Veiga, R., Nganga, D., Minga, A., Cros, B., Butler, C., Fenn, M., Long, C., and Stowe, L.: Aerosol-associated changes in tropical stratospheric ozone following the eruption of Mount Pinatubo, J. Geophys. Res., 99, 8197-8211, 1994.

Hadjinicolaou, P. and Pyle, J.: The recent turnaround in stratospheric ozone over northern middle latitudes: a dynamical modeling perspective, Geophys. Res. Lett., 32, doi:10.1029/2005GL022476, 2005.
Hall, T. and Plumb, R.: Age as a diagnostic of stratospheric transport, J. Geophys. Res., 99, 1059-1070, 1994.

Hall, T., Waugh, D., Boering, K., and Plumb, R.: Evaluation of transport in stratospheric models, J. Geophys. Res., 104, 18815 $18839,1999$.

Heimann, M.: The Global Atmospheric Tracer Model TM2, Tech. Rep. 10, DRKZ-Hamburg, 1995.

Heimann, M. and Keeling, C.: A three-dimensional model of atmospheric $\mathrm{CO}_{2}$ transport based on observed winds: 2: Model description and simulated tracer experiments, Geophys. Mon., 55, 237-275, 1989.

Holton, J., Haynes, P., McIntyre, M., Douglass, A., and Rood, R.: Stratosphere troposphere exchange, Rev. Geophys., 33, 403-439, 1995.

Houweling, S., Dentener, F., and Lelieveld, J.: The impact of nonmethane hydrocarbon compounds on tropospheric photochemistry, J. Geophys. Res., 103, 10 673-10 696, 1998.

Jöckel, P., von Kuhlmann, R., Lawrence, M., Steil, B., Brenninkmeijer, C., Crutzen, P., Rasch, P., and Eaton, B.: On a fundamental problem in implementing flux-form advection schemes for tracer transport in 3-dimensional general circulation and chemistry transport models, Q. J. R. Meteorol. Soc., 127, 1035$1052,2001$.

Krol, M., Houweling, S., Bregman, B., van den Broek, M., Segers, A., van Velthoven, P., Peters, W., Dentener, F., and Bergamaschi, P.: TM5, a global two-way nested chemistry transport zoom model: algorithm and applications, Atmos. Chem. Phys., 5, 417432, 2005, http://www.atmos-chem-phys.net/5/417/2005/.

Laat, A., Landgraf, J., Aben, I., Hasekamp, O., and Bregman, B.: Assimilated winds for global modelling: evaluation with space- and balloon-borne ozone observations, J. Geophys. Res., in press, 2006

Legras, B., Pisso, I., Berthet, G., and Lefévre, F.: Variability of the Lagrangian turbulent diffusion in the lower stratosphere, Atmos. Chem. Phys., 5, 1605-1622, 2005, http://www.atmos-chem-phys.net/5/1605/2005/.

Mahowald, M., Plumb, R. A., Rasch, P. J., del Corral, J. Sassi, F., and Heres, W.: Stratospheric transport in a threedimensional isentropic coordinate model, J. Geophys. Res., 107, doi:10.1029/2001JD001313, 2002.

Manney, G., Allen, D., Krüger, K., Naujokat, B., Santee, M., Sabutis, J., Pawson, S., Swinbank, R., Randall, C., Simmons, A. J., and Long, G.: Diagnosic comparison of meteorological analyses during the 2002 Antarctic winter, J. Atmos. Sci., 133, 1261-1278, 2005

Manson, A., Meek, C., Koshyk, J., Franke, S., Fritts, D., Riggin, D., Hall, C., Hocking, W., MacDougall, J., Igarashi, K., and Vincent, R.: Gravity wave activity and dynamical effects in the middle atmosphere (60-90 km): observations from an MF/MLT radar network, and results from the Canadian Middle Atmosphere Model (CMAM), J. Atmos. Solar-Terr. Phys., 64, 65-90, 2002.

Marchand, M., Godin, S., Hauchecorne, A., Lefévre, F., and Chipperfield, M.: Influence of polar ozone loss on northern midlatitude regions estimated by a high-resolution chemistry transport model during winter 1999/2000, J. Geophys. Res., 108, 8326, doi:10.1029/2001JD000906, 2003.

Meijer, E., Bregman, B., and van Velthoven, P.: The influence of data assimilation on the age of air calculated with a global 
chemistry-transport model using ECMWF winds, Geophys. Res. Lett., 31, doi:10.102/2004/GL021158, 2004.

Noije, T. P. C., Eskes, H. J., van Weele, M., and van Velthoven, P. F. J.: Implications of the enhanced Brewer-Dobson circulation in European Centre for Medium-Range Weather Forecasts reanalysis ERA-40 for the stratosphere-troposphere exchange of ozone in global chemistry transport models, J. Geophys. Res., 109, doi:10.1029/2004JD004586, 2004.

Peters, W., Krol, M. C., Dentener, F. J., and Lelieveld, J.: Identification of an El Niño-Southern Oscillation signal in a multiyear global simulation of tropospheric ozone, J. Geophys. Res., 106, 10 389-10 402, 2001.

Polavarapu, S., Ren, S., Rochon, Y., Sankey, D., Ek, N., Koshyk, J., and Tarasick, D.: Data assimilation with the Canadian Middle Atmosphere Model, Appl. Opt., 43, 77-100, 2005.

Prather, M.: Numerical advection by conservation of second-order moments, J. Geophys. Res., 91, 6671-6681, 1986.

Randel, W., Wu, F., III, J. R., Roche, A., and Waters, J. W.: Seasonal cycles and QBO variations in stratospheric $\mathrm{CH}_{4}$ and $\mathrm{H}_{2} \mathrm{O}$ observed in UARS HALOE data, J. Atmos. Sci., 55, 163-185, 1998.

Randel, W., Fleming, E., Geller, M., Gelman, M., Hamilton, K., Karoly, D., Ortland, D., Pawson, S., Swinbank, R., Udelhofen, P., Wu, F., Baldwin, M., Chanin, M.-L., Keckhut, P., Simmons, A., and Wu, D.: The SPARC intercomparison of Middle Atmosphere Climatologies, Tech. Rep. 20, SPARC newsletter, 2003.

Rotman, D., Atherton, C., Bergmann, D., Cameron-Smith, P., Chuang, C., Connell, P., Dignon, J., Franz, A., Grant, K., Kinnison, D., Molenkamp, C., Proctor, D., and Tannahill, J.: IMPACT, the LLNL 3-D global atmospheric chemical transport model for the combined troposphere and stratosphere: Model description and analysis of ozone and other trace gases, J. Geophys. Res., 109, doi:10.1029/2003JD003155, 2004.

Russel, G. and Lerner, J.: A new finite-differencing scheme for the tracer transport equation, J. Appl. Meteorol., 20, 1483-1498, 1981.

Russel-III, J., Gordley, L., Park, J., Drayson, S., Hesketh, D., Cicerone, R., Tuck, A., Frederick, J., Harries, J., and Crutzen, P.: The Halogen Occultation Experiment, J. Geophys. Res., 98, 10777-10797, 1993.

Scheele, R., Siegmund, P., and van Velthoven, P.: Stratospheric age of air computed with trajectories based on various 3-D-Var and 4-D-Var data sets, Atmos. Chem. Phys., 5, 1-7, 2005, http://www.atmos-chem-phys.net/5/1/2005/.

Schoeberl, M., Douglass, A., Zhu, Z., and Pawson, S.: A comparison of the lower stratospheric age-spectra, derived from a General Circulation Model and two data assimilation systems, J. Geophys. Res., 108, 4113, doi:10.1029/2002JD002652, 2002.

Searle, K., Chipperfield, M., Bekkie, S., and Pyle, J.: The impact of spatial averaging on calculated polar ozone loss, 1 , Model experiments, J. Geophys. Res., 103, 25 397-25 408, 1998.

Segers, A., van Velthoven, P., Bregman, B., and Krol, M.: On the computation of mass fluxes for Eulerian transport models from spectral meteorological fields, in: Proceedings of the 2002 International Conference on Computational Science, Lecture Notes in Computer Science (LNCS), Springer Verlag, 2002.

Shepherd, T., Koshyk, J., and Ngan, K.: On the nature of large-scale mixing in the stratosphere and mesosphere, J. Geophys. Res., 105, 12 433-12 446, 2000.
Simmons, A., Hortal, M., Kelly, G., McNally, A., Untch, A., and Uppala, S.: ECMWF analyses and forecasts of stratospheric winter polar vortex breakup: September 2002 in the Southern Hemisphere and related events, J. Atmos. Sci., 62, 668-689, 2005.

Stohl, A., Eckhart, S., Forster, C., James, P., Spichtinger, N., and Seibert, P.: A replacment of simple back trajectory calculations in the interpretation of atmospheric trace gas substance measurements, Atmos. Environ., 36, 4635-4648, 2002.

Stohl, A., Cooper, O., and James, P.: A cuationary note on the use of meteorological analysis data for quantifying atmospheric mixing, J. Atmos. Sci., 61, 1446-1453, 2004.

Strahan, S. E. and Polansky, B. C.: Meterological implementation issues in chemistry and transport models, Atmos. Phys. Chem., 6, 2895-2910, 2006.

Tan, D., Haynes, P. H., MacKenzie, A. R., and Pyle, J. A.: Effects of fluid-dynamical stirring and mixing on the deactivation of stratospheric chlorine, J. Geophys. Res., 103, 1585-1606, 1998.

Tan, W., Geller, M. A., Pawson, S., and da Silva, A.: A case study of excessive subtropical transport in the stratosphere of a data assimilation system, J. Geophys. Res., 109, doi:10.1029/2003JD004057, 2004.

Toon, G., Blavier, J.-F., Sen, B., Margitan, J., Webster, C., May, R., Fahey, D., Gao, R., Negro, L. D., Proffit, M., Elkins, J., Romashkin, P., Hurst, D., Oltmans, S., Atlas, E., Schauffler, S., Flocke, F., Bui, T., Stimpfle, R., Boone, G., Voss, P., and Cohen, R.: Comparison of MkIV balloon and ER-2 aircraft measurements of atmospheric trace gases, J. Geophys. Res., 104, 26779 $26790,1999$.

van Aalst, M., van den Broek, M., Bregman, A., Brühl, C., Steil, B., Toon, G., Garcelon, S., Hansford, G., Jones, R., Gardiner, T., Roelofs, G., Lelieveld, J., and Crutzen, P.: Tracer transport in the 1999/2000 Arctic polar vortex comparison of nudged GCM runs with observations, Atmos. Chem. Phys., 4, 81-93, 2004, http://www.atmos-chem-phys.net/4/81/2004/.

Van den Broek, M., Bregman, A., and Lelieveld, J.: Model study of stratospheric chlorine and ozone loss during the 1996/1997 winter, J. Geophys. Res., 105, 28 961-28 977, 2000.

van den Broek, M., van Aalst, M., Bregman, A., Krol, M., Lelieveld, J., Toon, G., Garcelon, S., Hansford, G., Jones, R., and Gardiner, T.: The impact of model grid zooming on tracer transport in the 1999/2000 Arctic polar vortex, Atmos. Chem. Phys., 3, 1833-1847, 2003,

http://www.atmos-chem-phys.net/3/1833/2003/.

Waugh, D. and Hall, T.: Age of stratospheric air: theory, observations, and models, Rev. Geophys., 40(4), doi:10.1029/2000RG000101, 2002.

Waugh, D., Hall, T. M., Randel, W. J., Rasch, P. J., Boville, B. A., Boering, K. A., Wofsy, S. C., Daube, B. C., Elkins, J. W., Fahey, D. W., Dutton, G. S., and Volk, C. M.: Three-dimensional simulations of long-lived tracers using winds from MACCM2, J. Geophys. Res., 102, doi:10.1029/97JD00793, 1997.

Wild, O., Sundet, J., Prather, M., Isaksen, I., Akimoto, H., Browell, E., and Oltmans, S.: CTM ozone simulations for spring 2001 iver the western Pacific: comparisons with TRACE-P lidar, ozone sondes and TOMS columns, J. Geophys. Res., 109, doi:10.1029/2003JD004041, 2003. 